\title{
Scattering of terahertz radiation from oriented carbon nanotube films
}

Eichhorn, Finn; Jepsen, Peter Uhd; Schroeder, Nicholas; Kozlowski, Gregory; Deibel, Jason A.; Koziol, Krzysztof K.K.

Published in:

Technical digest, CLEO/IQEC

Publication date:

2009

Document Version

Publisher's PDF, also known as Version of record

Link back to DTU Orbit

Citation (APA):

Eichhorn, F., Jepsen, P. U., Schroeder, N., Kozlowski, G., Deibel, J. A., \& Koziol, K. K. K. (2009). Scattering of terahertz radiation from oriented carbon nanotube films. In Technical digest, CLEO/IQEC (pp. IThC7). IEEE.

\section{General rights}

Copyright and moral rights for the publications made accessible in the public portal are retained by the authors and/or other copyright owners and it is a condition of accessing publications that users recognise and abide by the legal requirements associated with these rights.

- Users may download and print one copy of any publication from the public portal for the purpose of private study or research.

- You may not further distribute the material or use it for any profit-making activity or commercial gain

- You may freely distribute the URL identifying the publication in the public portal

If you believe that this document breaches copyright please contact us providing details, and we will remove access to the work immediately and investigate your claim. 


\title{
Scattering of Terahertz Radiation from Oriented Carbon Nanotube Films
}

\author{
Finn Eichhorn and Peter U. Jepsen \\ Department of Photonics Engineering, Technical University of Denmark, \\ Ørsteds Plads, Building 343, 2800 Kgs. Lyngby, Denmark \\ fiei@fotonik.dtu.dk \\ Nicholas Schroeder, Gregory Kozlowski, and Jason Deibel \\ Department of Physics, Wright State University, 3640 Colonel Glenn Hwy., Dayton, OH 45435 \\ jason.deibel@wright.edu \\ Krzysztof K.K. Koziol \\ Department of Materials Science and Metallurgy, University of Cambridge, \\ Pembroke St., Cambridge, CB2 3QZ, UK \\ kk292@cam.ac.uk
}

\begin{abstract}
We report on the use of terahertz time-domain spectroscopy to measure scattering from multi-walled carbon nanotubes aligned normal to the film plane. Measurements indicate scattering from the nanotubes is significantly stronger than for bulk metal.

(C)2009 Optical Society of America

OCIS codes: (300.6495) Spectroscopy, terahertz: (290.5820) Scattering measurements; (160.4236) Nanomaterials
\end{abstract}

Terahertz (THz) time-domain spectroscopy of carbon nanotubes has been used to investigate their optoelectronic properties [1-3]. These works focused on characterizing the frequency-dependent electronic and optical properties (refractive index, absorption, and conductivity) of a variety of configurations of carbon nanotubes. We present results examining the scattering of $\mathrm{THz}$ radiation from multi-walled carbon nanotubes oriented perpendicularly to the substrate plane. Despite the wavelength of the terahertz radiation $(0.3-3 \mathrm{~mm})$ being significantly larger that the diameters of the nanotubes, significant scattering of the incident terahertz radiation occurs. In fact, when compared to measurements performed on bulk metals, the scattering from the oriented nanotubes is significantly higher.

A commercial THz time-domain spectroscopy system with fiber-coupled photoconductive antennas is used to perform the scattering characterization. THz pulses are normally incident on the sample (0 degrees) and the scattered radiation is detected in reflection at several off-axis angles varying from 20 to 80 degrees (Fig. 1a). Wire-grid polarizers are placed in front of the transmitter and receiver antennas to insure which polarization component is incident on the samples and detected. The multi-walled carbon nanotube sample
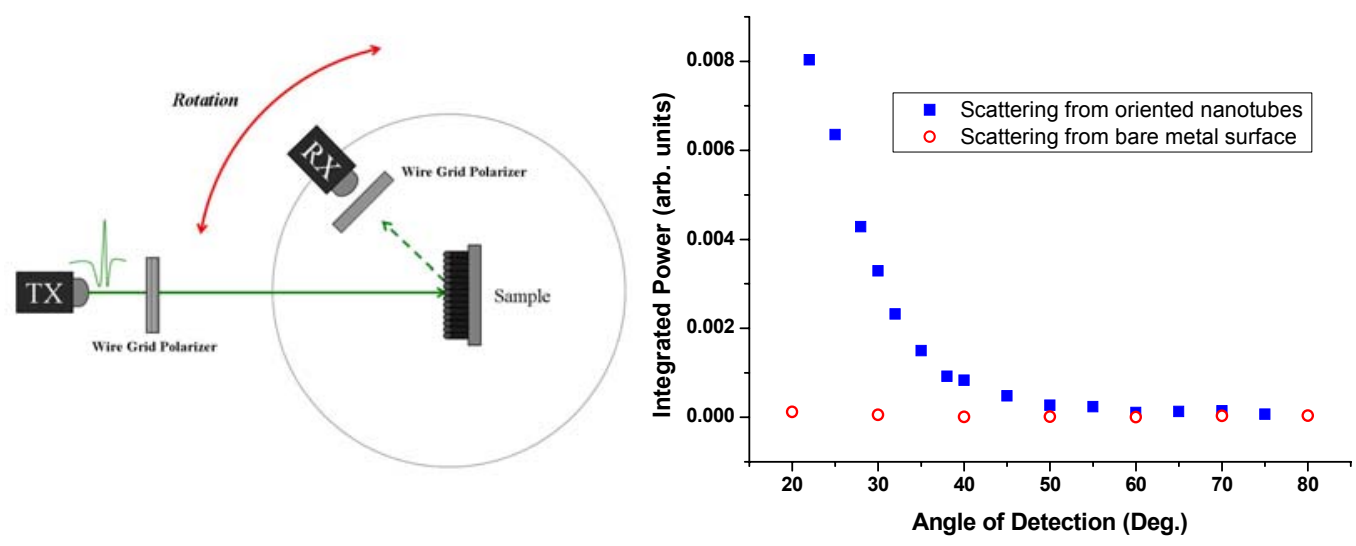

Fig. 1(a). Scattering characterization setup. (b) Scattered power versus detection angle from the carpet nanotubes and bulk metal. 


\section{IThC7.pdf}
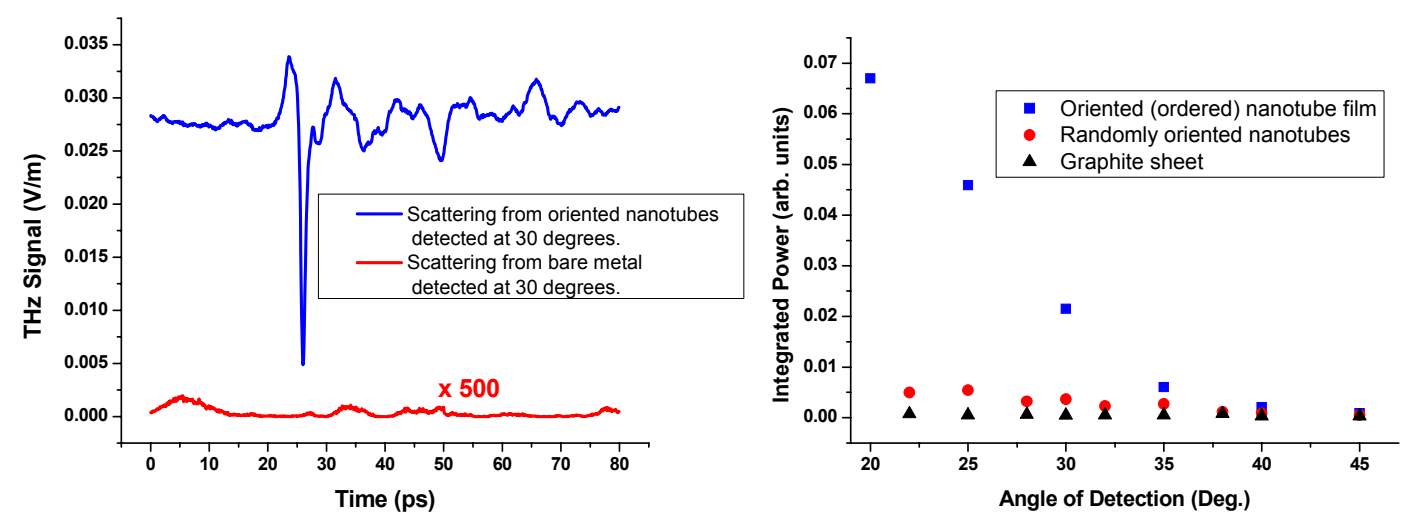

Fig. 2(a). Time-domain waveforms of the THz radiation scattered from the nanotubes and the bulk metal.

(b) Scattered power versus detection angle from the carpet nanotubes and bulk metal.

was grown via chemical vapor deposition to form carpet-like films consisting of nanotubes aligned approximately parallel to one another and normal to the plane of the glass substrate [4]. The approximate density of the carbon nanotubes in the carpet film is $5 \times 10^{6} \mathrm{~mm}^{-2}$.

Fig. 1(b) shows results from time-domain measurements on multi-walled carbon nanotubes in which the $\mathrm{THz}$ pulses are normally incident on the sample and the scattered radiation is detected in reflection at several off-axis angles. These results are compared to radiation scattered off of a bulk metal sample (brass), indicating that the scattering is greatly enhanced in the presence of the carpet-like film of nanotubes. The $\mathrm{THz}$ radiation scattered by the carpet falls off exponentially with increasing detection angle and does not return to an intensity level comparable to scattering from bulk metal until 60 degrees. THz scattering is not as pronounced when the experiment is performed with nanotubes aligned along the substrate plane. Fig. 2(a) compares the time-domain waveforms at the 30 deg. detection angle when the pulses are incident on the nanotube carpet and on bulk metal. It can be seen that the THz radiation scattered off of the carpet is significantly larger than that for bulk metal. While Fig. 2(a) shows only an $80 \mathrm{ps}$ long time window, actual measurements were performed over a much longer time window and no scattered radiation from the bulk metal at a magnitude comparable to that for the oriented nanotubes is present. Fig. $2 \mathrm{~b}$ provides evidence that the oriented alignment of the nanotube carpet is critical to this scattering phenomenon. $\mathrm{THz}$ radiation scattered from films of randomly oriented multi-walled carbon nanotubes and a sheet of graphite are more similar in magnitude to scattering from bulk metal than from oriented nanotubes. Preliminary analysis of the data in the frequency-domain indicates that the scattering is independent of frequency.

These results are counter-intuitive as the wavelength of the $\mathrm{THz}$ radiation is large enough that scattering from the nanotube carpets should not differ from the bulk metal with such significance. While the conductivity of brass is not the highest as compared to other metals, the conductivity of the nanotubes is not expected to be larger than for the brass metal. In fact, measurements of the back-reflected THz pulses (A pellicle beam-splitter was added to the setup) from both the metal and nanotube carpet shows that the reflected pulse from the brass is greater. It is only at off-axis points that the scattered radiation is greater from the nanotube carpet. Further studies will explore the effects of nanotube density, polarization dependence, and the variation of the incidence angle on this interesting scattering phenomenon.

\section{References}

[1] Maeng, I.H., C. Kang, S.J. Oh, J.-H. Son, K.H. An, and Y.H. Lee,"Terahertz electrical and optical characteristics of doublewalled carbon nanotubes and their comparison with single-walled carbon nanotubes," Appl. Phys. Lett., 90, pp. 051914 (2007).

[2] Jeon, T.-I., K.-J. Kim, C. Kang, S.J. Oh, J.-H. Son, K.H. An, D.J. Bae, and Y.H. Lee,"Terahertz conductivity of anisotropic single walled carbon nanotube films," Appl. Phys. Lett., 80(18), pp. 3403-5 (2002).

[3] Altan, H., F. Huang, J.F. Federici, A. Lan, and H. Grebel,"Optical and electronic characteristics of single walled carbon nanotubes and silicon nanoclusters by terahertz spectroscopy," J. Appl. Phys., 96(11), pp. 6685-9 (2004).

[4] Koziol, K., M. Shaffer, and A. Windle,"Three-Dimensional Internal Order in Multiwalled Carbon Nanotubes Grown by Chemical Vapor Deposition," Advanced Materials, 17(6), pp. 760-763 (2005). 